\title{
Tecnologias Sociais e produção de alimentos em municípios do Sudoeste Baiano. Conquistas e desafios na garantia da soberania alimentar camponesa.
}

\section{Social Technologies and food production in municipalities in Southwest Bahia. Achievements and challenges in guaranteeing peasant food sovereignty.}

\section{Tecnologías sociales y producción de alimentos en municipios del suroeste de Bahía. Logros y desafíos en la garantía de la soberanía alimentaria campesina.}

Eliane Pereira de Almeida ${ }^{1}$ https://orcid.org/0000-0002-8836-9026

Marcus Metri Corrêa ${ }^{2}$ https://orcid.org/0000-0002-9506-8969 Luciano Pires de Andrade ${ }^{3}$ http://orcid.org/0000-0001-5818-711X

\footnotetext{
1 Universidade Federal Rural de Pernambuco (UFRPE), Recife- PE-Brasil, eliane.pav@gmail.com

2 Universidade Federal Rural de Pernambuco (UFRPE), Recife- PE-Brasil, marcus.metri@gmail.com

${ }^{3}$ Universidade Federal do Agreste de Pernambuco -Garanhuns- PE, Brasil, lucianopandrade@gmail.com
}

Recebido em: 10/10/2021

Aceito para publicação em: 20/12/2021

\section{Resumo}

Este artigo objetiva analisar como se dá a produção de alimentos pelas famílias camponesas no Sudoeste Baiano, a partir do uso e apropriação das estruturas hídricas do Programa "Por Uma Terra e Duas Águas" (P1+2). Para tanto, delimitou-se o estudo em quatro municípios: Anagé, Bom Jesus da Serra, Cândido Sales e Poções. A metodologia adotada inclui a revisão de literatura, a pesquisa documental, o levantamento de dados primários e secundários, e entrevistas semiestruturadas, realizadas remotamente por conta da pandemia. Os resultados obtidos evidenciam que as tecnologias sociais do $\mathrm{P} 1+2$ exercem papel substancial para o cultivo de alimentos que compunham a dieta alimentar das famílias camponesas. No entanto, o período de estiagem ainda se apresenta como desafio para uma produção contínua.

Palavras-chave: Campesinato; Convivência com o Semiárido; P1+2.

\begin{abstract}
This article aims to analyze how food production is carried out by peasant families in Southwest Bahia, based on the use and appropriation of water structures in the "For One Land and Two Waters" Program (P1+2). Therefore, the study was delimited in four municipalities Anagé, Bom Jesus da Serra, Cândido Sales and Poções. The methodology adopted includes literature review,
\end{abstract}

Geopauta, Vitória da Conquista ISSN: 2594-5033, V. 5, n.4, 2021, e9638

Este é um artigo de acesso aberto sob a licença Creative Commons da CC BY 
documentary research, survey of primary and secondary data, and semi-structured interviews, carried out remotely because of the pandemic. The results obtained show that the P1+2 social technologies play a substantial role in the cultivation of foods that make up the diet of peasant families.

Keywords: Peasantry; P1+2; Coexistence with the Semiarid Region.

\section{Resumen}

Este artículo tiene como objetivo analizar cómo la producción de alimentos es realizada por las familias campesinas en el suroeste de Bahía, a partir del uso y apropiación de estructuras de agua en el Programa "Por una tierra y dos aguas" (P1 + 2). Por tanto, el estudio se delimitó en cuatro municipios Anagé, Bom Jesus da Serra, Cândido Sales y Poções. La metodología adoptada incluye revisión de literatura, investigación documental, relevamiento de datos primarios y secundarios y entrevistas semiestructuradas, realizadas de forma remota a causa de la pandemia. Los resultados obtenidos muestran que las tecnologías sociales P1 + 2 juegan un papel sustancial en el cultivo de alimentos que integran la dieta de las familias campesinas. Sin embargo, el período seco todavía se presenta como un desafío para la producción continua.

Palabras llave: Campesinato; Convivencia com el semiárido; P1+2.

\section{Introdução}

O Semiárido Brasileiro compreende 1.262 municípios distribuídos em dez estados federativos, sendo que nove encontram-se na Região Nordeste, espaço ocupado e explorado desde os tempos idos da colonização do Brasil, e, para entendê-lo, de forma a não o limitar às perspectivas positivistas e deterministas, requer uma leitura crítica socioeconômica de sua configuração, no tempo-espaço, atrelado a uma totalidade. (OLIVEIRA, 1977; ANDRADE, 1984; PRADO JUNIOR, 2004).

O movimento homogeneizante realizado pelo Estado, desde a segunda metade do século $X X$, com a produção, circulação, distribuição e consumo de produtos, para geração e acumulação de riquezas, tem suprimido as potencialidades naturais, sociais e econômicas desse espaço de existências múltiplas, bem como dificultando a expansão de ações alicerçadas sob os princípios da Agroecologia, da convivência com a semiaridez e da sustentabilidade. (CASTRO, 1996, 1986; SILVA, 2006; BARBOSA, 2012, 2014; BATISTA E CAMPOS, 2014) 
Todavia, no universo de questões que envolvem o ser e o viver do sertanejo, a produção de alimento se apresenta como uma das mais relevantes a ser trabalhada. E, nessa perspectiva, que a Articulação Semiárido Brasileiro (ASA) proporcionou no semiárido nordestino, especificamente no início do século XXI, um movimento mobilizador e articulador de políticas públicas que garantiram às famílias camponesas, o direito de ter acesso a água para a manutenção de sua existência, e, nesse universo existencial, a garantia de água para a produção de alimentos. Constrói-se, então, o Programa “Uma Terra e Duas águas" (P1+2), pela ASA junto ao Estado. (VALE; SANTOS, 2020)

Iniciado em 2007, o P1+2 faz parte do conjunto de ações estruturantes e formativas da política de convivência com o semiárido, que promoveu a continuidade da democratização da água, iniciada com o Programa “Um Milhão de Cisternas Rurais" (P1MC). Sua implementação "prioriza a segurança e soberania alimentar a partir da produção agroecológica de alimentos, [...]" (BARBOSA, 2009, $\mathrm{s} / \mathrm{n}$ ), e por meio de tecnologias sociais como as cisternas calçadão e enxurrada, barreiro trincheira, barragem subterrânea, tanque de pedra/caldeirão e bomba d'água popular, dentre outras. Se o P1MC possibilitou a democratização do acesso a água potável para beber e cozinhar, o P1+2 "arrematou-o" ao suprir as necessidades produtivas das famílias camponesas, na dimensão da garantia da existência, prioritariamente, mas, também, na possibilidade de geração de renda com a venda do excedente produtivo. (ASACOM, 2019)

Embora tenha sido executado no semiárido nordestino a partir de 2007, o P1+2 só começou a ser implementado no Território de Identidade Sudoeste Baiano, em 2012 sob a execução do CEDASB - Unidade Gestora Territorial (UGT) da ASA. Foram 1.149 tecnologias sociais construídas por meio de financiamento do governo federal, especificamente no primeiro mandato da Presidenta Dilma Rousseff (PT); 989 por financiamentos da PETROBRAS e Fundação Banco do Brasil (FBB); e 792 por meio de recursos oriundos do governo do estado da Bahia, especificamente no governo de Jaques Wagner (PT). 
Com a descontinuidade da política de convivência com o semiárido, não houve um avanço mais significativo do Programa P1+2, o que se apresenta como um fator de enfraquecimento do campesinato na dimensão regional e territorial, pois trava-se a possibilidade de melhorar, minimamente, a segurança alimentar das famílias.

As tecnologias sociais representam a convivência com o semiárido, que, por sua vez, se apresenta como um dos caminhos para a organização de uma sociedade comprometida com os princípios da Agroecologia, no que tange ao modo de vida, tanto no sentido da produção, mas sobretudo, quanto no aspecto da sua sociabilidade e relação com a natureza. As TS's são estratégias dotadas de técnica passível de reaplicação, de baixo custo de implementação, e descentralizadora, cuja a participação dos sujeitos na construção do conhecimento é condição que a caracteriza. Precisa estar comprometida com a "solução de demandas sociais concretas, vividas e identificadas pela população", como ratifica o Instituto de Tecnologia Social (ITS, 2004, p. 28). Se configuram como um dos caminhos de superação da concentração das águas no campo nordestino.

Assim sendo, adotou-se para a análise da pesquisa, a realidade de famílias camponesas contempladas com as tecnologias sociais do P1+2, nos municípios de Anagé, Bom Jesus da Serra, Cândido Sales e Poções, do Território Sudoeste Baiano. As escolhas dos municípios, das comunidades e das famílias aconteceram de forma aleatória, orientadas pelos contratos/convênios executados pelo CEDASB. Do universo de tecnologias sociais, priorizou-se as cisternas calçadão, cisterna enxurrada e os barreiros trincheiras.

A amostragem foi composta por 24 famílias camponesas, organizadas em três grupos compostos por oito famílias, cada grupo correspondente a uma tecnologia social. Essa arrumação metodológica e procedimental, permitiu a análise de variantes acerca da produção familiar a partir da tecnologia social implementada em sua terra, como por exemplo, diversidade e continuidade produtiva, bem como o gerenciamento da água armazenada. 
A pesquisa tem características exploratória e explicativa, qualitativa e quantitativa, por se dedicar a análise de um acontecimento/ação, do ponto de vista dos elementos que colaboram para sua ocorrência. Adotou-se como procedimentos metodológicos o levantamento bibliográfico, para buscar o estado da arte das abordagens pretendidas nesse trabalho; a pesquisa documental, que permitiu a análise interpretativa de fontes primárias de informações e dados (GIL, 2002; LAKATOS e MARCONI, 2003), disponibilizados pelo CEDASB, entidade responsável pela execução do programa $\mathrm{P} 1+2$ nas localidades selecionadas. A documentação institucional foi disponibilizada após solicitação formal devidamente justificada. Foram realizadas pesquisas em sites institucionais e governamentais, como a Agência Nacional de Águas (ANA), o Instituto Nacional de Meteorologia e Clima tempo, no intuito de averiguar a incidência das secas nos municípios em questão.

Para entender as nuances da produção de alimentos das famílias camponesas, adotou-se enquanto técnica de coleta de dados as entrevistas semiestruturadas, cuja principal característica é a possibilidade de flexibilização do seu roteiro base (COLOGNESE; MÉLO, 1998). As entrevistas ocorreram virtualmente, pela plataforma meet, por chamadas de vídeo (WhatsApp), e por ligação telefônica, devido ao contexto de pandemia ainda vigente. Foi realizada, também, pesquisa bibliográfica, especificamente estudos de caso, que pudessem favorecer um comparativo da realidade em diferentes territórios, sobre o universo do temário desse trabalho. Os dados coletados foram tratados por meio de leitura analítica e comparativa, sistematizados e organizados para a elaboração de gráficos, quadros, tabelas e texto.

Destarte, munido desse aparato metodológico é que este trabalho objetiva entender como se dá a dinâmica da produção de alimentos pelas famílias camponesas, por meio da utilização e apropriação das tecnologias sociais do P1+2, bem como apreender os avanços e desafios encontrados nesse processo. 
Tecnologia social de convivência com o semiárido. Estratégia de adaptação às mudanças climáticas.

Nos últimos 40 anos têm-se abordado sobre os rumos do planeta frente ao modus operandi da sociedade mundial, principalmente no que tange a sua relação com a natureza. Todavia, foi na década de 1990 que o assunto foi tratado com uma perspectiva mais operacional, no sentido de resolução coletiva e de corresponsabilidade entre os países do mundo.

O Protocolo de Kyoto, assinado em 1997 e vigorado desde 2005, é considerado um marco das discussões ambientais, por pautar metas concretas de redução de gases de efeito estufa na atmosfera do planeta. Os países precisariam repensar o paradigma de desenvolvimento adotado, mas, o que aconteceu foi a adoção de estratégias de se "burlar" a responsabilidade, como se traduziu na lógica do crédito de carbono entre países, relação díspare entre os mais ricos e poluidores, detentores de tecnologias de alto padrão, com as localidades fornecedoras de fontes de filtragem do ar, geralmente, países em outro patamar de "desenvolvimento". (VENTURA, et al, 2012),

O temário sobre mudanças climáticas, de forma séria e deliberativa, está às margens das agendas dos países capitalistas, enquanto a natureza já mostra os impactos da ação antrópica em seu curso e equilíbrio. A comunidade científica mundial, continua a sinalizar da necessidade de se adotar práticas sociais, econômicas, e ambientais mais sustentáveis para não colapsar o planeta.

Nesse cenário, os estudos sinalizam que as regiões semiáridas e áridas serão as localidades que mais sofrerão com os impactos ambientais. O semiárido brasileiro, por exemplo, nos últimos 30 anos teve sua área modificada algumas vezes, como mostra os registros na Tabela 1. É nesse contexto, e de sua superação, é se tem a necessidade de implementação de estratégias que promovam uma relação mais sustentável da sociedade com os recursos naturais disponibilizados pela natureza.

A observação dos dados da tabela 1, possibilita identificar a progressão do número de municípios inseridos enquanto semiáridos, desde 1989, quando da 
primeira delimitação da Região Semiárida brasileira realizada pela Superintendência de Desenvolvimento do Nordeste (SUDENE). Essa agregação socioespacial de municípios obedeceu alguns critérios orientadores e classificatórios como o índice pluviométrico, a considerar a "média anual igual ou inferior a $800 \mathrm{~mm}$ de precipitação (BRASIL, 1989). Assim, teve-se uma área formada por 1031 municípios.

\section{Tabela 1- Configurações quantitativas das delimitações do semiárido Brasileiro, por} estado, nos anos 1989, 2005 e 2017.

\begin{tabular}{|c|c|c|c|c|}
\hline \multirow{2}{*}{ Estado } & \multirow{2}{*}{$\begin{array}{l}\text { Qtd. de municípios da } \\
\qquad \mathrm{UF}^{*}\end{array}$} & \multicolumn{3}{|c|}{ Qtd. de municípios do Semiárido Brasileiro } \\
\hline & & 1989 & 2005 & 2017 \\
\hline Alagoas & 102 & 35 & 38 & 38 \\
\hline Bahia & 417 & 257 & 265 & 278 \\
\hline Ceará & 184 & 134 & 150 & 175 \\
\hline Minas Gerais & 853 & 40 & 85 & 91 \\
\hline Maranhão & 217 & 0 & 0 & 2 \\
\hline Paraíba & 223 & 170 & 170 & 194 \\
\hline Pernambuco & 185 & 118 & 122 & 123 \\
\hline Piauí & 224 & 109 & 127 & 185 \\
\hline Rio Grande do Norte & 167 & 140 & 147 & 147 \\
\hline Sergipe & 75 & 28 & 29 & 29 \\
\hline & Total & 1.031 & 1.133 & 1.262 \\
\hline
\end{tabular}

Fonte: BRASIL (1989, 2005, 2017); IBGE (2019)

Elaboração: Eliane Almeida (2019).

*Unidade Federativa

Em 2005, além do critério da média anual, foi também considerado o índice de aridez de até 0,5, registrado entre 1961 a 1990, e o risco de seca maior que $60 \%$ com base no período ente 1970 a 1990 (BRASIL, 2005). Essa mudança de critérios elevou para 1133 o número de municípios semiáridos no Brasil, e um acréscimo de 8,66\% na sua extensão territorial, que era de $892.309,4 \mathrm{~km}^{2}$ e que passou a ser $969.589,4 \mathrm{~km}^{2}$. E, em 2017, o semiárido brasileiro passou a representar 1.128.697 $\mathrm{KM}^{2}$ do território nacional, com 1.232 municípios. Dessa vez o critério classificatório adicionado foi o percentual diário de déficit hídrico igual ou superior a 60\%. (Mapa 1)

Apesar de existir questões transversais nas delimitações territoriais do semiárido, as quais não se pretende elencar nesse trabalho, é mister que o processo da ampliação da semiaridez nos municípios relaciona-se às práticas antrópicas que 
culminam na destruição da natureza e da subtração de seus recursos naturais, inclusive a água. 

soberania alimentar camponesa.

ALMEIDA, E.P.; CORREA, M.M.; ANDRADE, L.P.

Mapa 1- Delimitação territorial da região semiárida do Brasil (1989-2017)
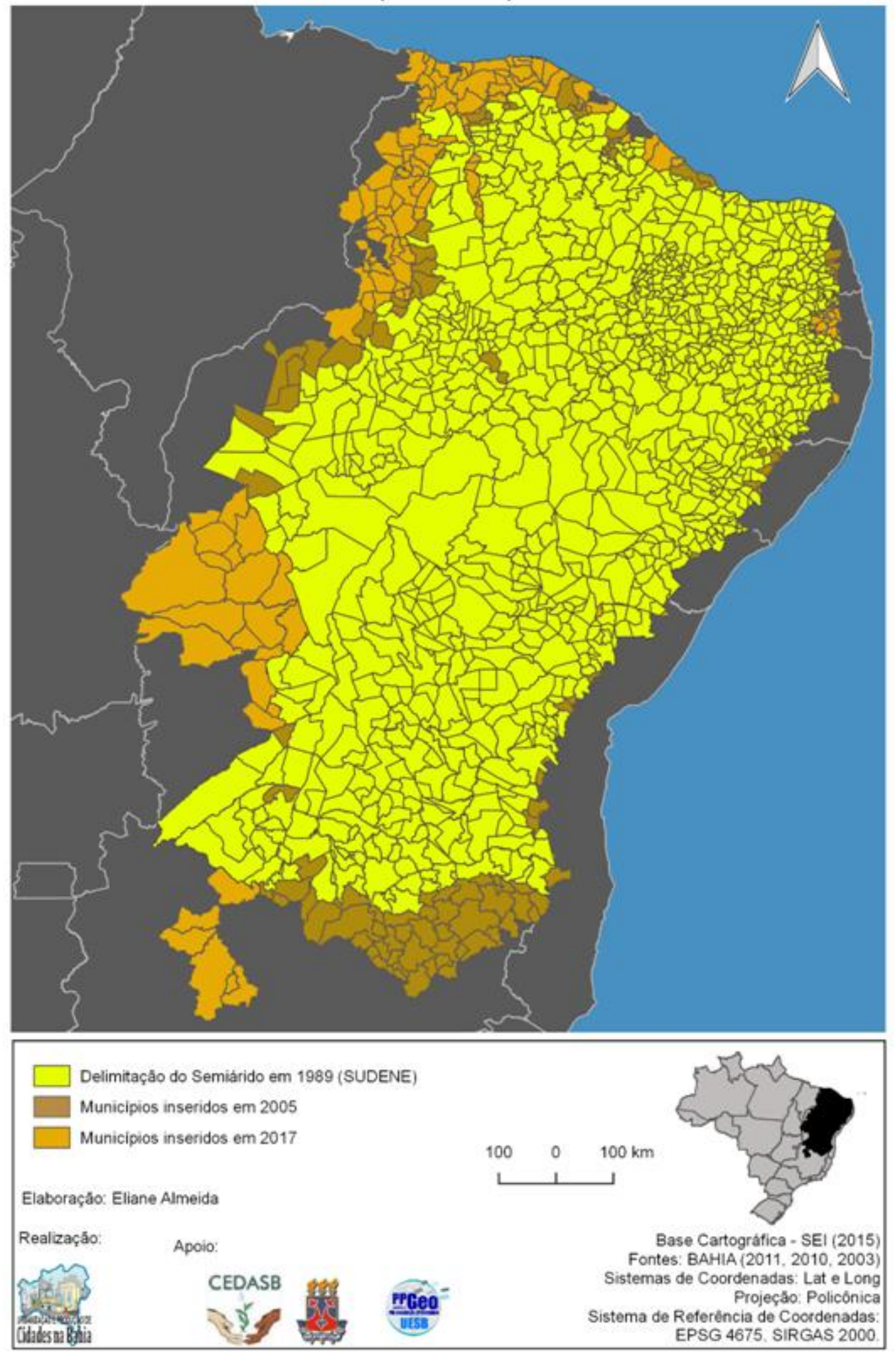

Fonte: Elaborado por Almeida (2018)

Geopauta, Vitória da Conquista ISSN: 2594-5033, V. 5, n.4, 2021, e9638 
Esse desequilibro estruturado pelas sociedades com relação a apropriação dos recursos naturais para prover as suas necessidades, faz com que sejam urgentes o desenvolvimento de estratégias que possam possibilitar a existência e reprodução integral da população do semiárido brasileiro, e, de forma peculiar, das populações camponesas.

Compreende-se por estratégias de impacto local de forma eficaz e eficiente, as denominadas Tecnologias Sociais. As TS's para a convivência com o semiárido, são, por exemplo, para as Organizações da Sociedade Civil (OSC's), instrumentos de difusão, consolidação e construção do conhecimento, que surge das experiências acumuladas pelas famílias camponesas. Refere-se a práxis que tem na técnica empreendida de forma contextualizada, os princípios da Agroecologia.

"Conjunto de técnicas, metodologias transformadoras, desenvolvidas e/ou aplicadas na interação com a população e apropriadas por ela, que representam soluções para inclusão social e melhoria das condições de vida". (ITS, 2004, p. 26)

Essa definição do Instituto de Tecnologia Social (ITS) coaduna com a forma como as organizações sociais compreendem e desenvolvem as TS's, no caso aqui destacado, as organizações que trabalham a convivência com o semiárido, a partir das ações da ASA. Dar visibilidade ao que se configura tecnologia social, é de suma importância para contribuir com possíveis avanços de políticas públicas e/ou ações autônomas por meio de práticas sóciotécnicas aplicadas, que se configuram enquanto soluções eficazes para determinadas realidades. Do contrário, não as apreender seria deixá-las na invisibilidade, o que não possibilitaria reconhecer seu potencial transformador. (ITS, 2004)

Utiliza-se, também, o termo "tecnologias contextualizadas" para tratar do conjunto de técnicas, práticas, saberes e metodologia desenvolvidas no semiárido, na perspectiva da "Convivência com o semiárido".

[...] as tecnologias contextualizadas devem combinar esses dois aspectos: o resgate e a valorização dos saberes e das motivações da população sertaneja e as práticas e instrumentos tecnológicos apropriados àquela realidade. $\mathrm{O}$ objetivo principal deve ser gerar 
formas produtivas inovadoras, com base em práticas apropriadas de manejo e uso dos recursos naturais, priorizando as tecnologias ajustadas às condições ecológicas da semiaridez, proporcionando melhorias nas condições de vida da população local e aumentando a produtividade da economia sertaneja. (SILVA, 2006, p. 190)

É importante frisar que embora ainda não se tenha um consenso sobre a definição de tecnologia social, a abordagem trazida por Silva (2006) alerta que, para o semiárido, a tecnologia social que lhe serve, é aquela que esteja contextualmente inserida na realidade sertaneja, que os sujeitos possam ter participação ativa no processo de sua implementação, que seu manejo seja tangível, e que sua estrutura possibilite autonomia e independência de gestão.

É nessa perspectiva defendida por Silva (2006) que se enquadra as tecnologias sociais de convivência com o semiárido, que são know-how das organizações da Articulação Semiárido Brasileiro (ASA). Essa expertise está relacionada ao seu objetivo primaz que é garantir que as famílias camponesas do semiárido tenham acesso a água de qualidade para existir com mais dignidade.

A consolidação da ASA se deu em contextos de manifestações populares contra a inércia do Estado frente aos flagelos intensificados nos longos períodos de estiagem; a ineficácia das políticas públicas adotadas para amenização dos impactos das secas no território nordestino; e a rejeição do discurso do "combate às secas" como sendo um viés promovedor de soluções estruturantes para a região. (VALE; SANTOS, 2020)

Em 2002 a ASA constituiu-se como personalidade jurídica, e se inseriu na esfera propositiva de políticas públicas de convivência com o semiárido nordestino, junto ao Estado, bem como, na mobilização social para a difusão de um paradigma diferenciado no trato às questões climáticas, especificamente, do acesso a água no sertão, por meio de tecnologias sociais (Idem). Já implementou no semiárido brasileiro 626.791 mil cisternas para armazenamento de 16 mil litros de água para o consumo das famílias camponesas; 6.848 cisternas em escolas rurais com capacidade de armazenar 52 mil litros de água; 103.528 tecnologias sociais para subsidiar a 
produção agrícola em pequena escala; e 793 casas comunitárias de semente. (ASABRASIL, 2021)

Esse arcabouço sociotécnico, em sinergia com as realidades sertanejas, tornouse contraposição às políticas públicas estatais que não coadunam com a lógica e a capilaridade dos projetos de convivência com o semiárido. $\mathrm{O}$ baixo custo orçamentário de suas tecnologias sociais, a fácil aplicabilidade, apropriação e manuseio, a eficiência, e a harmônica agregação ao agroecossistema das unidades de produção familiar (UPF), são características que ratificam que as TS's são parte de um projeto consistente de fortalecimento do campesinato do semiárido nordestino.

\section{Análise da produção de alimentos de familias camponesas por meio do Programa} P1+2.

Antes de se adentrar nas especificidades acerca da produção de alimentos das famílias camponesas, é importante compreender como está configurada a política de convivência com o semiárido, de modo mais específico, os Programas do P1MC e $\mathrm{P} 1+2$. Em referência ao P1+2, especificamente, percebe-se que representa uma espacialidade de abrangência ainda incipiente no Sudoeste Baiano (Figura 1), como também no semiárido Nordestino, pois ainda contabiliza pouco mais de 103 mil estruturas hídricas de captação de água de chuva de subsidio à produção agrícola implementadas até então. (ASA, 2021)

Como já mencionado anteriormente, as TS's de convivência com o semiárido, tem como foco principal o armazenamento das águas pluviais para o suprimento das necessidades das famílias do campo. Nesse trabalho, ateve-se à análise do Programa "Uma terra e Duas águas", especificamente, da cisterna calçadão, da cisterna enxurrada e do barreiro trincheira. 
Infográfico 1 - Comparação dos percentuais e quantidades de tecnologias sociais dos Programas P1MC e P1+2, implementadas pelo CEDASB, nos municípios da pesquisa, até 2021.

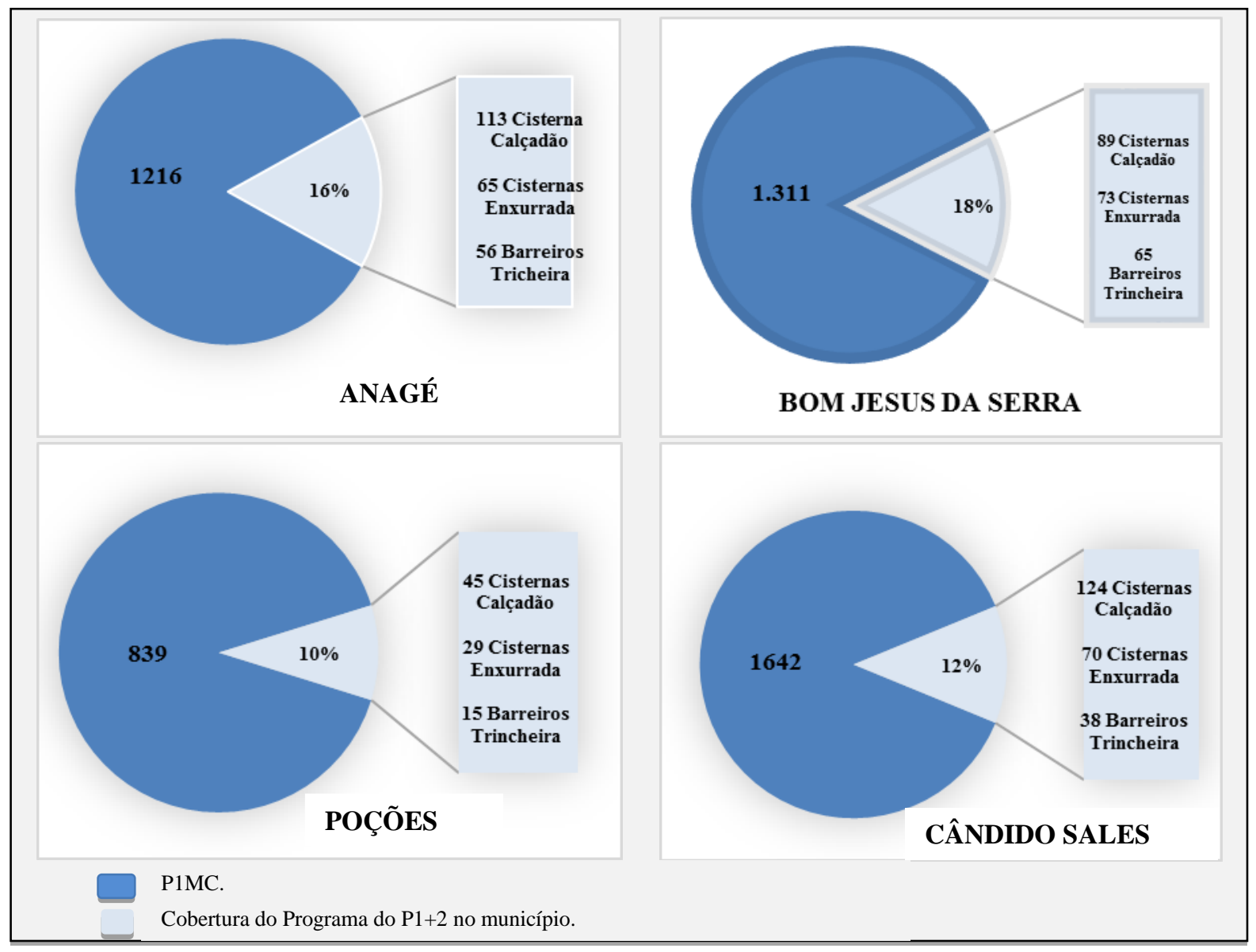

Fonte: Pesquisa documental, CEDASB (2021)

Sistematização e elaboração: Eliane Almeida.

A sistematização das informações dos grupos entrevistados, organizados por tecnologia social, possibilitou a identificação de especificidades do ser e viver numa região semiárida, no caso específico do trabalho em questão, em seu caráter produtivo. A análise da realidade mostrou, primeiramente, que as famílias desenvolvem a gestão da água seguindo a lógica da necessidade latente do momento, por ordem de prioridades (Gráficos 1 e 2). 


\section{Gráfico 1 - Gestão familiar da água das Cisternas Calçadão,}

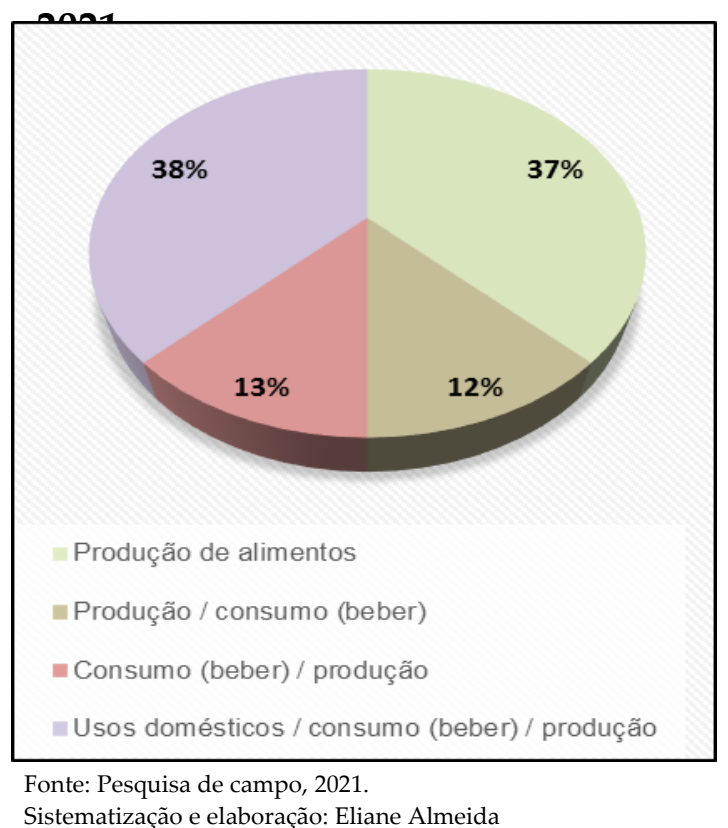

Gráfico 2 - Gestão familiar da água das Cisternas Enxurrada, 2021.

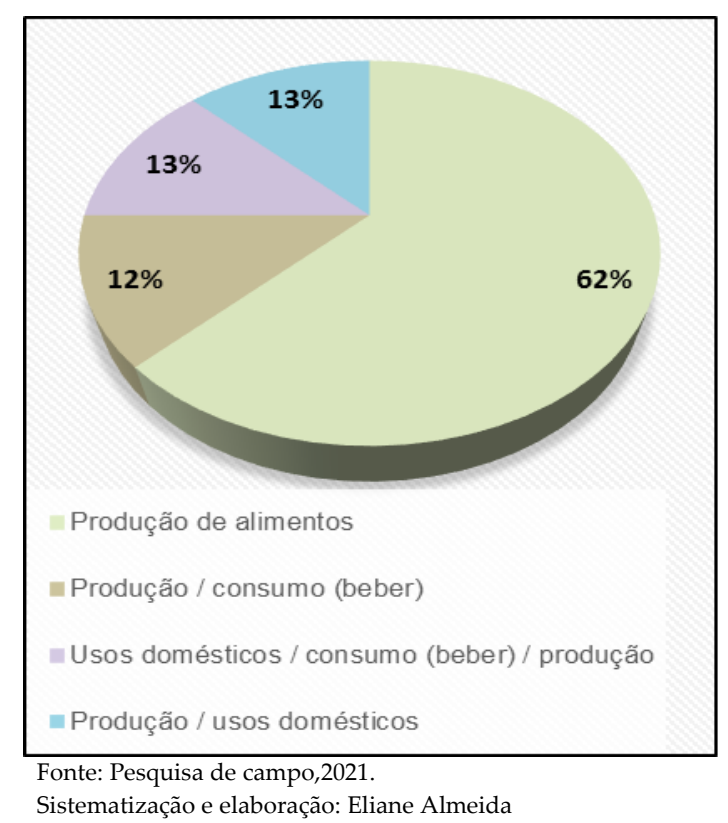

No gráfico 1, ao observar a ordem de prioridade, é possível apreender o múltiplo uso e destinação do recurso hídrico na rotina das famílias camponesas, inclusive para suprir um déficit existente no que tange a água para o consumo familiar. É importante frisar que para uma família receber uma TS do P1+2, necessariamente ela precisa ter sido contemplada com o P1MC. Ao priorizar esse aspecto, inferiu-se duas possibilidades para tal questão emergente: a primeira é que, o uso da água da cisterna calçadão para o consumo familiar (beber) relaciona-se com a ineficiente gestão da água pelas famílias da cisterna de 16 mil litros, cuja funcionalidade primaz é a destinação para o consumo da familiar e o preparo de sua alimentação, e a segunda é que, diante de períodos de estiagens tão intensos e prolongados, as famílias desenvolveram como alternativa, uma subgestão dentro da gestão dos recursos hídricos.

A escuta dos sujeitos permitiu ratificar que, por mais que exista certa "indisciplina" na gestão da "água de beber", que também é destinada aos afazeres domésticos, é o período de seca prolongado que recondiciona a administração dos recursos hídricos disponíveis. Atualmente, tem-se o esvaziamento das aguadas 
comunitárias; a diminuição e/ou suspensão das ações emergenciais do exército nos municípios com a "Operação Carro Pipa"; e a dificuldade financeira de comprar água para beber ( $\mathrm{R} \$ 120,00$ a $\mathrm{R} \$ 150,00$ a contratação de um carro pipa de 8 mil litros de água). Toda essa situação faz com que as famílias gerenciem as tecnologias sociais de forma que, muitas vezes, contrapõem a definição e funcionalidade que a própria ASA difunde. No entanto, a realidade se apresenta mais complexa do que as teorias, os conceitos e as definições.

O diálogo construído, por meio das entrevistas, com órgãos ligados direto ou indiretamente com a distribuição de água nas comunidades rurais, como secretarias de agricultura e Defesas Civil, permitiu visualizar mais uma variante que se soma à temática do acesso a água nos municípios da pesquisa, e como isso se reverbera no locus dos camponeses/as.

Trata-se do abastecimento emergencial das famílias em período de secas prolongadas, principalmente pela denominada Operação "Carro Pipa" executada pelo Exército e o poder público municipal. Tal situação encontra-se da seguinte forma: em Anagé, com 25.516 hab. e desses 20.592 residentes no campo, dispõe, atualmente, de 25 carros pipa; Bom Jesus da Serra, com 10.113 hab., sendo que 7.345 são moradores/as do campo, dispunha de apenas 5 carros pipa; Candido Sales, com 27.918 hab. sendo 8.632 domiciados no campo, tem apenas 3 carros pipa disponíveis, e, por fim, Poções com 44.701 hab., desses 10.042 moradores/as do campo, tem a disposição 22 carros pipa (IBGE, 2010; PESQUISA DE CAMPO, 2021)

É importante salientar que, as famílias que correspondem 37\% ilustrado no gráfico 1, e que usam a água somente para produzir alimento, enfatizaram que essa priorização se dará até quando tiverem em outras aguadas a oportunidade de suprir as demandas domésticas, e enquanto a cisternas de 16 mil litros não secar, todo reservatório que puder dar suporte a família será utilizado. Percebeu-se, portanto, que a produção de alimento aparece em níveis de prioridades diferentes por apresentar-se em dinâmicas sociais diversa de disponibilidade de recursos hídricos. 
Outra realidade que se coaduna com a discussão desenvolvida, é de famílias que tem a cisterna calçadão, que em um contexto como o citado acima, acabam por abastecer a vizinhança, que em sua maioria são familiares, para que tenham água para beber e cozinhar, principalmente, quando se encontram desprovidos da água em suas cisternas de "primeira água". Encontrou-se, por exemplo, uma família composta por 8 pessoas, que partilha da água de sua cisterna calçadão com outras duas famílias, igualmente numerosa.

Ao direcionar a análise para o gráfico 2, e compará-lo com o gráfico 1, evidencia-se que as famílias contempladas com a cisterna enxurrada utiliza a água armazenada, preponderantemente, para a produção de alimentos. Essas famílias, em sua maioria, dispunham de outras fontes hídricas, como poços artesianos e cacimbas, que suprem os afazeres domésticos como o lavar louças, roupas, e limpeza da casa em geral, e dessa forma não demandam tanto a utilização da água das TS's.

Mas, para outras famílias, que é minoria dentro da amostragem trabalhada nesse trabalho, a água armazenada também é consumida, por não se ter outras fontes, quando as cisternas de 16 mil litros secam. Ao relatarem o manuseio da água da tecnologia social, as famílias explicaram que a cisternas de enxurrada, é de grande valia, mas que sua manutenção é trabalhosa, pois entra grande quantidade de sedimentos, geralmente de matéria orgânica e/ou da lixiviação do solo. Mesmo com a decantação dos sedimentos, a água armazenada ainda fica barrenta na maioria das cisternas. Por isso, foca-se na produção de alimentos e nos afazeres domésticos.

Ao verificar como essa apropriação e gestão da água se deu com as famílias contempladas com os barreiros trincheiras, encontrou-se uma realidade um pouco diferenciada (Gráfico 3). Por se tratar de uma estrutura com capacidade de armazenar quase 10 vezes a quantidade de água das cisternas calçadão e enxurrada, o barreiro trincheira é uma tecnologia sociais que garante as famílias maior comodidade no sentido do atendimento das demandas diárias de manutenção das atividades domésticas. No entanto, a produção de alimentos, embora apareça no 
montante dos $63 \%$, como uma destinação prioritária em segunda instância, realiza-se com menos foco, continuidade e diversidade.

Gráfico 3 - Gestão familiar da água dos barreiros trincheira, por prioridade, 2021.

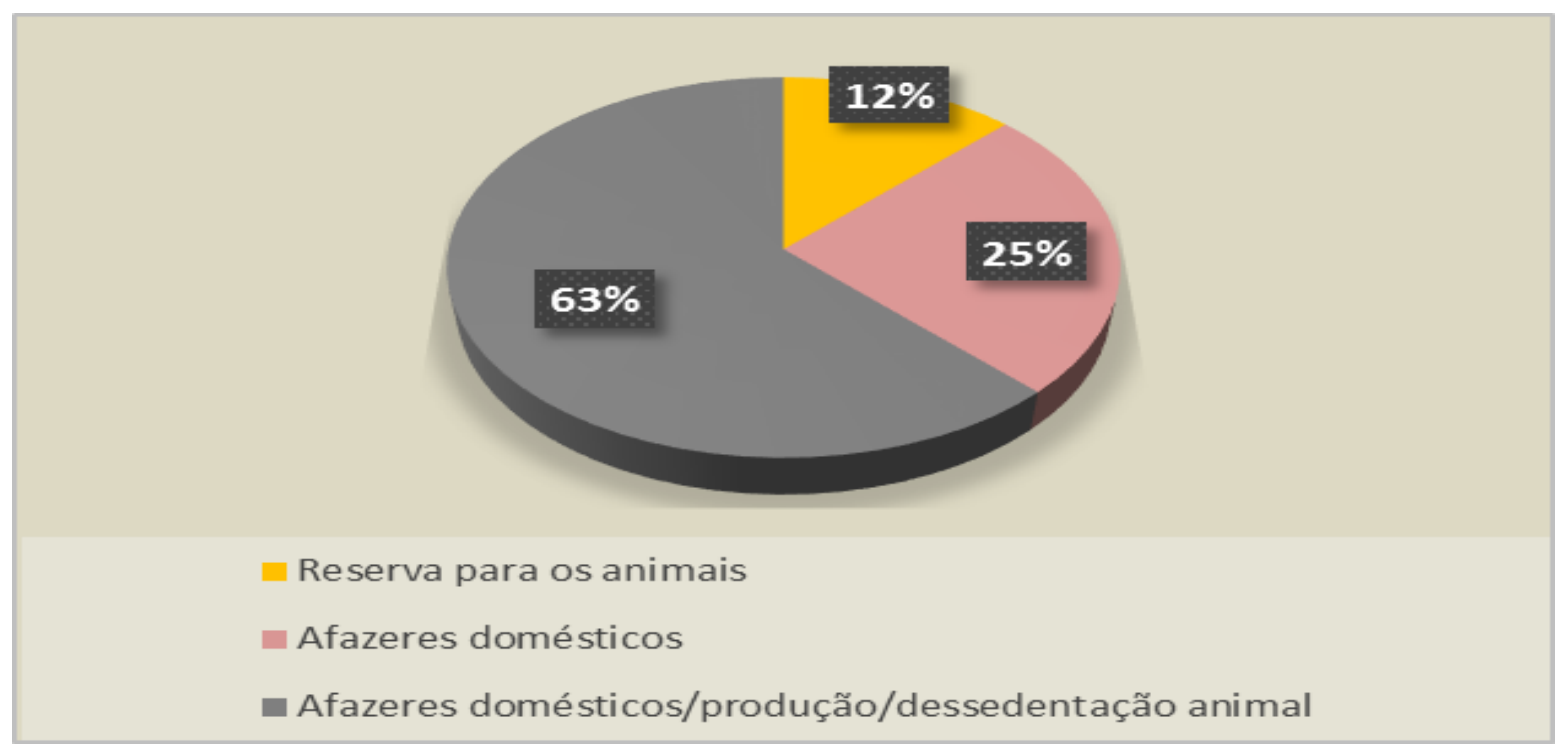

Fonte: Pesquisa de campo, 2021.

Sistematização e elaboração: Eliane Almeida.

Foi possível identificar que, em duas das oito famílias que tem o barreiro trincheira, a doação de água para a vizinhança faz parte da rotina. Como são $500 \mathrm{~m}^{3}$ de água, elas se sentem no dever de acolher as demandas da comunidade, principalmente em períodos de seca onde até a água para beber fica escassa, e as cisternas de 16 mil litros esvaziam. Uma das famílias entrevistadas, enfatizou: “eu não nego água né, eu dou água pra todo mundo que quiser levar. Qualquer pessoa. [...] já doei uns sete caminhões de água aqui" (informação verbal)4. O caminhão o qual o agricultor se refere é o caminhão pipa, e o período é o vigente, com o registro de dois anos sem uma chuva substanciosa.

No sentido de viabilizar a compreensão do universo da diversidade produtiva das famílias, sistematizou-se a produção agrícola das famílias a partir da água

\footnotetext{
${ }^{4}$ Entrevista realizada com o agricultor Edilson Pereira da Paixão, da Comunidade Lagoa de Baixo em Bom Jesus da Serra/BA, por Eliane Almeida, em 27 de junho de 2021. Entrevista online (Whatsapp).
} 
armazenada nas três tecnologias sociais de convivência com o semiárido, no período que compreende a implementação até o ano de 2020 (Tabela 1).

Tabela 1 - Relação de alimentos produzidos pelas famílias, por tecnologia social, entre os anos de 2010 a 2020.

\begin{tabular}{|c|c|c|c|}
\hline \multirow[b]{2}{*}{ Alimentos } & Cisterna Calçadão & Cisterna Enxurrada & Barreiro Trincheira \\
\hline & $\begin{array}{c}\text { Qtd. de } \\
\text { Famílias cultivadoras }\end{array}$ & \begin{tabular}{|c|} 
Qtd. de \\
Famílias cultivadoras \\
\end{tabular} & $\begin{array}{c}\text { Qtd. de } \\
\text { Famílias cultivadoras }\end{array}$ \\
\hline Alface, coentro & 8 & 8 & 5 \\
\hline Coentro & 8 & 8 & 5 \\
\hline Cebolinha & 6 & 8 & 5 \\
\hline Couve & 7 & 6 & 4 \\
\hline Repolho & 2 & 3 & - \\
\hline Tomate & 1 & - & - \\
\hline Beterraba & 6 & 7 & 4 \\
\hline Salsa & 4 & - & - \\
\hline Rúcula & 1 & 1 & - \\
\hline Cenoura & 7 & 7 & 4 \\
\hline Pimenta & 4 & 1 & - \\
\hline Abóbora & 3 & 1 & 4 \\
\hline Quiabo & 2 & 1 & 1 \\
\hline Açafrão & 2 & - & - \\
\hline Maxixe & 2 & - & 1 \\
\hline Cebola (cabeça) & 2 & 3 & 2 \\
\hline Feijão/fava/andu & 2 & 5 & 3 \\
\hline Milho & 1 & 3 & 2 \\
\hline Pimentão & - & 1 & 1 \\
\hline Pepino & - & 1 & 1 \\
\hline Batatinha & - & 3 & - \\
\hline Alho & - & 2 & - \\
\hline Urucum & - & 2 & 1 \\
\hline Batata-doce & - & 1 & 1 \\
\hline Chuchu & - & 1 & - \\
\hline Berinjela & - & 1 & - \\
\hline Mandioca & - & - & 1 \\
\hline Caxixe & - & - & 1 \\
\hline
\end{tabular}

Fonte: Pesquisa de campo (jun/jul de 2021)

Sistematização e elaboração: Eliane Almeida

Observa-se, que as famílias que receberam as cisternas de enxurrada trazem mais experiências produtivas, em termo de diversidade, do que as famílias que tem as cisternas calçadão. Tal fato pode ser interpretado pela premissa de que, como a água da cisterna calçadão destina-se a várias demandas das famílias como para beber e os afazeres domésticos, a produção acaba por ser menos diversa, para manter o equilíbrio no atendimento da totalidade das demandas. 
Todavia, em ambas tecnologias se percebeu uma base alimentar familiar nutritiva e diversa, pautada no cultivo de verduras e hortaliças. No caso dos barreiros trincheira, o levantamento constatou que as experiências produtivas se deram mais no início de sua implementação, a maioria das famílias não teve uma prática contínua de plantios nos arredores dessa TS, e a justificativa dada por elas é que os barreiros se localizam distantes das casas e dos quintais, cerca de 300 a 1000 metros.

Todos/as entrevistados/as enfatizaram que a terra ao redor do barreiro é "fraca" e "ruim". Por isso a sua funcionalidade, nos últimos três anos, resume-se em garantir reserva hídrica para o uso doméstico e para os animais (bovinos, suínos, aves e equinos). A produção de alimentos encontra-se numa escala para consumo familiar, e com diversidade reduzida, menos para uma família que conseguiu instalar um sistema de bomba hidráulica para levar a água do barreiro para reservatórios alternativos localizados no seu quintal, garantindo a água para os afazeres domésticos e para a produção de hortaliças, verduras e frutíferas.

Retomando a análise das famílias sobre os tipos de solo onde se escava o barreiro, a hipótese que se levanta é que a ausência de um estudo de solo mais especializado na identificação dessas áreas, a TS acaba não atingindo seu potencial no cumprimento da funcionalidade social a qual foi concebida. Os solos das localidades estudadas são classificados como Latossolos e Argissolos. Os latossolos caracterizam-se por serem, em sua maioria, bons retentores de água, todavia ácidos e pobres em nutrientes, e exige um manejo planejado e intenso para garantir produtividade, qualidade e diversidade de alimentos às famílias. Já os argissolos são solos de baixa fertilidade, suscetíveis à compactação e erosão, possuem, em algumas localidades, sedimentos rochosos em sua estrutura, e também necessitam de correção de acidez e um manejo de adubação eficiente. Apresentam variantes em toda extensão do semiárido baiano, por isso a análise do solo se configura como medida essencial para quaisquer fins. (CUNHA, et.al., 2010; FILHO, et. Al., 2006) 
Ao acionar a instituição executora do P1+2 nas localidades - o CEDASB, para verificar o seu entendimento sobre essa questão, a mesma informou que considera pertinente o aspecto questionado, para garantir a efetividade e eficácia da tecnologia. No entanto, esclareceu que não há no plano de trabalho dos projetos do $\mathrm{P} 1+2$ a análise de solos. E, soma-se a essa questão, o curto prazo que a instituição tem no cumprimento das metas acordadas nos contratos, o que inviabiliza, por exemplo, a construção de possíveis parcerias na promoção das análises de solos necessárias para maior segurança na implementação dos barreiros trincheira, e para orientação sobre o manejo da área onde se vai produzir.

Retomando o foco para a diversidade da produção, notou-se a presença de muitas plantas medicinais, consideradas a "farmácia natural" das famílias. A água armazenada possibilitou o cultivo durante todo o ano de muitas dessas plantas. Destacam-se o Hortelã $(54 \%)$, capim santo $(50 \%)$, a erva-cidreira $(37,5 \%)$, boldo e alecrim (25\%), arruda (17\%), alfavaca, poeijo, alevante e erva-doce (12,5\%), almeirão, "girama", manjericão, alfazema, corama e losna (4\%), palminha de horta (8\%). Dentre as frutíferas destacou-se o cultivo de banana, mamão e laranja (29\%), romã, goiaba, limão e melancia (17\%), manga, acerola e abacate $(12,5 \%)$, abacaxi, noni, coco verde, pocan, jaca, graviola e maracujá (8\%), caju, cana, pinha e pitanga (4\%).

Com esse aparato de informações que a pesquisa conseguiu captar, foi possível perceber que as tecnologias do Programa P1+2 são para as famílias camponesas instrumentos essenciais de manutenção de sua existência. Outros estudos sobre esse temário, também convergem para essa assertiva, como o trabalho de Santos (2017) que mostrou a diversidade produtiva das famílias camponesas, em comunidades do município de Retirolândia, no Território do Sisal, após a implementação das tecnologias sociais do P1+2. A renda familiar de $70 \%$ das famílias dessa pesquisa, foi complementada pela comercialização dos excedentes produtivos, nos programas institucionais como o PAA e PNAE, como nas feiras livres. 35\% dessas famílias conseguem garantir, pelo menos, um salário mínimo com essa comercialização. 
Nessa mesma perspectiva, o estudo de caso realizado por Silva e Teixeira (2015) no Território do Sertão do Araripe, em Pernambuco, evidenciou como o P1+2 propicia a variedade vegetal de um sistema agroecológico, no caso, o quintal produtivo familiar. Mapeou-se cerca de 69 espécies vegetais cultivadas entre roçado, forrageiras, frutíferas, hortaliças e medicinais, e identificou uma tímida prática de comercialização desses alimentos, e priorização do autoconsumo.

A análise realizada por Alencar (et al., 2018) sobre os impactos do programa na diversificação agropecuária no extremo sul do estado do Ceará, utilizando o método Propensity Score Matching (PSM), também se conclui a importância das tecnologias sociais do P1+2 para a garantia de uma dieta alimentar diversificada e nutritiva para as famílias do campo, por ser possibilitada a produção em um período mais dilatado.

Ressalta-se, nesses trabalhos, a necessidade de ampliação do programa, para que um número maior de famílias agricultoras, consigam ter uma melhoria na sua qualidade de vida. Esclarecem, a urgência de ações complementares, ou concomitantes, as ações estruturantes, em destaque a assistência técnica e extensão rural, para que se possa consolidar com mais eficiências a transição agroecológicas, e todo conhecimento difundido no processo de execução do programa nas localidades.

Em consonância ao exposto, a realidade analisada nesse artigo, também identificou que $100 \%$ das famílias, antes do P1+2, não tinham o hábito e as condições materiais de produzirem verduras, hortaliças e frutas. Dessa forma, só consumiam esse tipo de alimento, caso as condições financeiras permitissem, o que era uma raridade. Atualmente, conforme descrição na tabela 1, mesmo diante as intepéries climáticas, conseguem garantir uma alimentação mais completa.

Em suma, as tecnologias sociais da ASA, devidamente apropriadas pelas famílias, promoveu às famílias a oportunidade de produzirem e consumirem os seus próprios alimentos, de forma agroecológica, e, em alguns casos, proporcionou a geração de renda monetária com a venda de excedentes. Nesse trabalho, pode trazer as minudências que se entrelaçam no cotidiano, dimensão da vida capaz de inquietar 
teorias, questionar e avaliar modelos sociotécnicos no âmbito do campesinato, e das suas condições peculiares de reprodução social.

\section{Considerações finais}

Nos últimos 2 anos os municípios do Sudoeste baiano têm sidos impactados com a estiagem, e, como já é sabido, é no campo que esses impactos se reverberam com mais precisão, pois afeta diretamente o cotidiano e dinâmica produtiva, social, econômica e cultural da população camponesa.

De julho de 2019 a julho de 2021, houve a incidência de secas graves, moderadas e fracas no Sudoeste baiano. Somente entre os meses de outubro a dezembro de 2020, não se registrou secas na região (BRASIL, 2021). Essa situação climática, somada ao aumento continuo e progressivo da destruição da natureza, numa perspectiva sistêmica, faz com que no semiárido as mudanças socioeconômicas tendem a ser mais pontuais.

Todavia, diante de tantas variabilidades, é possível compreender, como mostrou a pesquisa, que a produção de alimentos, mesmo com as TS's, ainda está, imbricadamente, relacionada a escassez de recursos hídricos, por isso, os multiusos da água das estruturas hídricas do programa P1+2, pelas famílias. Todavia, foi possível identificar que, na ordem de prioridade, a produção de alimentos ocupa lugar de significância.

É inconteste a relevância das TS's para a garantia da diversidade e qualidade dos alimentos consumidos pelas famílias, de sua soberania e segurança alimentar. No entanto, não se pode desconsiderar questões transversais que impactam no uso e gestão da água armazenada, como os períodos de estiagens, intensos e longos, que tem afetado a continuidade da diversidade alimentar, e condicionado parte das famílias às compras externas, ou a subtração desses alimentos na dieta familiar. Nesse contexto de estiagem mencionado, a estratégia familiar é o multiuso da água das cisternas e barreiros, para além das definições referentes às suas funcionalidades. 
Outro aspecto averiguado nesse trabalho, é que se faz importante que as organizações da ASA reflitam sobre o sistema de captação da água da cisterna enxurrada, muito questionado pelas famílias, principalmente, pela quantidade de sedimentos que se deposita no seu interior e nos decantadores, o que dificulta a manutenção da estrutura. Assim também, os barreiros trincheiras requer estudos mais detalhados de solo, para que, após a escavação, a tecnologia de fato possa ser mais eficiente diante das demandas das famílias.

Na perspectiva de contribuir para que a convivência com o semiárido seja melhor consolidada nas comunidades rurais, é que se sugere a inserção no plano de ação do Programa P1+2 um acompanhamento técnico, após ou concomitante a implantação das TS's, para contribuir com as famílias no processo de manejo e gestão dos subsistemas, pois dessa forma seria mais efetiva à sua apropriação integral pelos camponeses/as.

\section{Referências}

ALENCAR, M. O; ALVES, D. F.; JUSTO, W. R; ARAUJO, J. A. Impactos do P1+2 sobra a diversificação agropecuária. Revista Política Agrícola. Ano XXVII, jul./ago./set. 2018. p. 45-59

ANDRADE, M. C. Formação Econômico-social e Processos Políticos no Nordeste Brasileiro. In: MARANHÃO, Sílvio. (org.). A Questão Nordeste. Estudos sobre formação Histórica, Desenvolvimento e Processos Políticos e Ideológicos. Rio de Janeiro. Editora Paz e Terra. 1984, p. 31-40.

ASABRASIL. Programa uma terra e duas águas (P1+2). Disponível em: https://www.asabrasil.org.br/acoes/p1-2. Acesso em: 10 de jul. 2021.

ASABRASIL. Mapa de tecnologias. Disponível em:

https://www.asabrasil.org.br/mapatecnologias. Acesso em 25 de jun.2021.

ASABRASIL. Tecnologias Sociais para a convivência com o semiárido. Série Estocagem de água para a produção de alimentos. Cisterna Calçadão. 10ª edição. Recife. ASACom. 2014.

ASABRASIL. Tecnologias Sociais para a convivência com o semiárido. Série Estocagem de água para a produção de alimentos. Cisterna Enxurrada. $6^{a}$ edição. Recife. ASACom. 2014. 
ASABRASIL. Tecnologias Sociais para a convivência com o semiárido. Série Estocagem de água para a produção de alimentos. Barreiro Trincheira. 5ª edição. Recife. ASACom. 2014.

BAPTISTA, Naidison; CAMPOS, Carlos. Por um modelo sustentável de desenvolvimento no semiárido. In: CONTI, Irio L. et al. (Org.). Construindo saberes, cisternas e cidadania: Formação para a convivência com o semiárido brasileiro. Ed. IABS, Brasília-DF, 2014. p. 53-54.

BAPTISTA, Naidison; CAMPOS, Carlos. Caracterização do semiárido brasileiro. In: CONTI, Irio L et al. (Org.). Convivência com o Semiárido Brasileiro: Autonomia e Protagonismo Social. Ed. IABS, Brasília-DF, 2014. p. 55-62.

BAPTISTA, Naidison; CAMPOS, Carlos. A convivência com o semiárido e suas potencialidades. In: CONTI, Irio L.; SCHROEDER, Edni O. (Org.). Convivência com o Semiárido Brasileiro: Autonomia e Protagonismo Social. Ed. IABS, Brasília-DF, 2014. p. 63-70.

BARBOSA, A. G. Acesso a água é uma questão de direito. Ecodebate. Publicado em 22 de abril de 2009. Disponível em: www.ecodebate.com.br/2009/04/22/acesso-aagua-e-uma-questao-de-direito-artigo-de-antonio-gomes-barbosa/. Acesso em 23 de maio de 2021.

BARBOSA, A. G. “Água é direito”. 2012. In: Blog Territórios Livres do Baixo Parnaíba. Disponível em: <http://territorioslivresdobaixoparnaiba.blogspot.com>. Acesso: 27 mai. 2021.

BARBOSA, A. G. Debatendo o Semiárido II - Seca de 1991 a 1993. A ocupação da SUDENE como marco da vida dos povos do semiárido. 2014. Blog O Semiárido é Belo. Disponível em: <http://osemiaridoebelo.com >. Acesso: 27 mai. 2018.

BRASIL. Cartilha: Nova delimitação do semi-árido brasileiro. Ministério da Integração, 2005. Disponível em https://www.docsity.com/pt/nova-delimitacao-dosemi-arido-brasileiro/4782461. Acesso: 4 fev. 2019.

BRASIL. Agência Nacional das Águas. Monitor de Secas. Disponível em: http://monitordesecas.ana.gov.br/mapa?mes=7\&ano=2021. Acesso: 03 de set. 2021.

BRASIL. Lei $\mathbf{n}^{\mathbf{0}} \mathbf{7 . 8 2 7}$ de 27 de setembro de 1989. Regulamenta o art. 159, inciso I, alínea c, da Constituição Federal, institui o Fundo Constitucional de Financiamento do Norte - FNO, o Fundo Constitucional de Financiamento do Nordeste - FNE e o Fundo Constitucional de Financiamento do Centro-Oeste - FCO, e dá outras providências. Brasília. 1951. Disponível em:

http://www.planalto.gov.br/ccivil_03/LEIS/L7827.htm. Acesso: 3 de mai. 2019.

CASTRO, Iná Elias de. Seca versus Seca. Novos interesses, Novos territórios, Novos discursos no Nordeste. In: CASTRO, I. E. de.; GOMES, P. C. da C.; CORRÊA, R. L. 
(org). Brasil: questões atuais da reorganização do território. Rio de Janeiro. Bertrand Brasil, 1996.

CASTRO, Iná Elias de. $\mathbf{O}$ mito da necessidade: discurso e prática do regionalismo nordestino. Rio de Janeiro. Bertrand Brasil, 1986.

COLOGNESE, S. A.; MÉLO, J. L. B. de. A técnica de entrevista na pesquisa social. Cadernos de Sociologia, Porto Alegre, v. 9, p. 143 - 159, 1998.

CUNHA, T.J.F; PETRERE; V.G; SILVA.D.J.; MENDES, A.M.S.; MELO, R.S.; NETO, M.B.O.; SILVA, M. S. L.; ALVAREZ, I. A. Principais solos do Semiárido

tropical brasileiro: caracterização, potencialidades, limitações, fertilidade e manejo. In: Semiárido Brasileiro: Pesquisa, Desenvolvimento e Inovação. Petrolina/PE, Embrapa Semiárido, 2010, 402 p. ISBN: 978-85-7405-012-6

FILHO, J.F.M.; SOUZA, A. L.V. O manejo e a conservação do solo no Semi-árido baiano: desafios para a Sustentabilidade. Revista Bahia Agrícola. v.7, n.3, nov. 2006, ISSN 1414-2368.

GIL, Antônio Carlos. Como elaborar projetos de pesquisa. $4^{a}$ ed. - São Paulo, Editora Atlas, 2002.

ITS. Caderno de Debate. Tecnologias Sociais no Brasil. Direito à ciência e ciência para a cidadania. São Paulo. Editora Raiz. 2004.

MARCONI, M. A.; LAKATOS, E. M.; Fundamentos de metodologia científica. $5^{a}$ edição. São Paulo. Editora Atlas, 2003.

OLIVEIRA, Francisco de. Elegia para uma Re(li)gião. Sudene, Nordeste.

Planejamento e Conflito de Classes. 2a Ed. Rio de Janeiro, Editora Paz e Terra, 1977.

PRADO JUNIOR, Caio. História econômica do Brasil. São Paulo: Brasiliense, 2004.

SANTOS, K.F.S. O Programa “Uma Terra e Duas Águas - P1+2” como

instrumento político- pedagógico e social na promoção da

segurança alimentar e nutricional. Revista Macambira. v. 1, n. 1, p 84. (2017) ISSN 2594-4754

SILVA, T. C; TEIXEIRA, C. T. M. Quintal produtivo agroecológico: enfoque estratégico de convivência com o semiárido - um estudo de caso. Congresso Latinoamericano de Agroecologia. La Plata/Argentina, 2015.

SILVA. Roberto Marinho A. Entre o Combate à Seca e a Convivência com o Semiárido: transições paradigmáticas e sustentabilidade do desenvolvimento. 2006. 298f. Tese (Doutorado em Desenvolvimento Sustentável) - Centro de Desenvolvimento Sustentável, Universidade de Brasília, Brasília, 2006. 
VALE, E.P.A.; SANTOS, J. A ASA e a luta contra o discurso do combate à seca. Revista GeoNordeste. São Cristovão, Ano XXXI, n.2, p. 40-58, jul./dez. 2020.

VENTURA, A.C.; et.al. Tecnologias sociais: as organizações não governamentais no enfrentamento das mudanças climáticas e na promoção de desenvolvimento humano. Cadernos EBAPE.BR. v.10, nº 3. Rio de Janeiro, set. 2012.

Contribuição dos/as autores/as: Autora 1: Pesquisa bibliográfica, elaboração textual e iconográfica, discussão dos resultados.

Autor 2: Análise dos resultados e revisão textual. Autor 3: Análise dos resultados e revisão textual. 